\title{
Predictors of survival and toxicity in patients on adjuvant therapy with 5-fluorouracil for colorectal cancer
}

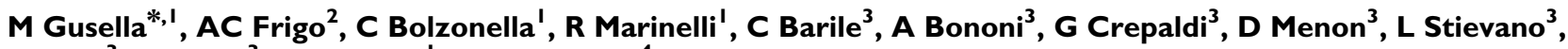 \\ S Toso ${ }^{3}$, F Pasini ${ }^{3}$, E Ferrazzi' and R Padrini ${ }^{4}$ \\ 'Laboratory of Pharmacology and Molecular Biology, Oncology Department, Azienda-ULSS I 8-Rovigo, Via Ugo Grisetti 265, 45027 Trecenta, Italy; \\ ${ }^{2}$ Department of Environmental Medicine and Public Health, University of Padova, via Loredan 18, 35 I 31 Padova, Italy; ${ }^{3}$ Medical Oncology, Oncology \\ Department, Azienda ULSS I 8-Rovigo, Viale Tre Martiri 89, 45100 Rovigo, Italy; ${ }^{4}$ Department of Clinical and Experimental Medicine, University of \\ Padova, via Giustiniani 2, 35128 Padova, Italy
}

\begin{abstract}
The present study aimed at investigating whether the simultaneous evaluation of pharmacokinetic, pharmacogenetic and demographic factors could improve prediction on toxicity and survival in colorectal cancer patients treated with adjuvant 5-fluorouracil (5FU)/leucovorin therapy. One hundred and thirty consecutive, B2 and C Duke's stage colorectal cancer patients were prospectively enrolled. 5FU pharmacokinetics was evaluated at the first cycle. Thymidylate synthase (TYMS) 5'UTR and $3^{\prime} \cup T R$ polymorphisms and methylenetetrahydrofolate reductase (MTHFR) C677T and AI298C polymorphisms were assessed in peripheral leukocytes. Univariate and multivariate analyses were applied to evaluate which variables could predict chemotherapy-induced toxicity, disease-free survival (DFS) and overall survival (OS). Multivariate analysis showed that: (a) low 5FU clearance was an independent predictive factor for severe toxicity $(O R=7.32 ; P<0.0001)$; (b) high-5FU clearance predicted poorer $D F S(H R=1.96$; $P=0.041)$ and $O S(H R=3.37 ; P=0.01 I) ;(c)$ advanced age was associated with shorter $D F S(H R=3.34 ; P=0.0008)$ and $O S$ $(H R=2.66 ; P=0.024)$; (d) the C/C genotype of the MTHFR C677T polymorphism was protective against grade 3-4 toxicity $(P=0.040)$; (e) none of the TYMS polymorphisms could explain 5FU toxicity or clinical outcome.

British Journal of Cancer (2009) I 00, I549-1557. doi:I0.1038/sj.bjc.6605052 www.bjcancer.com
\end{abstract}

Published online 2I April 2009

(c) 2009 Cancer Research UK

Keywords: fluorouracil; adjuvant therapy; colorectal cancer; pharmacokinetics; pharmacogenetics.

Fluorouracil $(5 \mathrm{FU})$ is a fundamental component of all chemotherapic combinations for palliative (Board and Valle, 2007) and adjuvant treatments (Chung and Saltz, 2007) of colorectal cancer. Its main mechanism of action consists of inhibition of thymidylate synthase (TS) through an active metabolite, fluorodeoxyuridine monophosphate (FdUMP), which forms an inactive ternary complex with TS and 5-10 methylenetetrahydrofolate (MTHF) (Pinedo and Peters, 1988). Intracellular MTHF levels, which are essential for ternary complex stabilisation, are controlled by the enzyme methylenetetrahydrofolate reductase (MTHFR) (Scott and Weir, 1994). Consequently, the tissue activities of TS and MTHFR are presumed to be major determinants of $5 \mathrm{FU}$ clinical response. The activity of both enzymes is under genetic control and several gene polymorphisms are known to influence their tissue expression. A variable number of $28 \mathrm{bp}$ tandem repeats (VNTR) is present in the $5^{\prime}$-untranslated region $\left(5^{\prime}\right.$-UTR) of the TS gene (TYMS). The allele containing the triple repeat (3R) is associated with 3-4-fold translational efficiency, compared with the double repeat allele (2R) (Kawakami et al, 2001). A second polymorphism has been identified in the second $28 \mathrm{bp}$ repeat of $3 \mathrm{R}$ alleles,

\footnotetext{
*Correspondence: Dr M Gusella;

E-mail: milenagusella@libero.it

Received 4 December 2008; revised I 8 March 2009; accepted 25 March 2009; published online 21 April 2009
}

consisting of a G>C base change at the twelfth nucleotide, which makes the transcriptional activity of the $3 \mathrm{R}$ allele as low as that of the 2R allele (Mandola et al, 2003). Third, a 6 bp deletion may occur in the $3^{\prime}$-untranslated region ( $3^{\prime}$-UTR) of TYMS, associated with decreased mRNA stability and lower TS expression (Mandola et al, 2004). Two functionally important single nucleotide polymorphisms (SNP) have also been detected in the MTHFR gene (MTHFR), C677T and A1298C, resulting in decreased MTHFR activity (Ulrich et al, 2002).

Despite these theoretical and experimental premises, clinical studies which have evaluated the effect of TYMS (Gusella and Padrini, 2007) and MTHFR (Robien et al, 2005) polymorphisms on the colorectal cancer response/toxicity to 5FU have produced inconsistent results.

An additional determinant of 5FU activity is the metabolic rate of dihydropyrimidine dehydrogenase (DPD), the enzyme responsible for 5FU inactivation (van Kuilenburg, 2004). Variability in DPD activity is only marginally explained by genetic factors, as deficient variants of DPD gene are extremely rare (van Kuilenburg et al, 2001). Hence, DPD activity is best determined by direct in vivo measurement of $5 \mathrm{FU}$ plasma clearance $(\mathrm{CL})$.

The aim of our work was to evaluate the clinical outcome and toxicity of colorectal cancer patients on adjuvant treatment with 5FU in relation with demographic characteristics, known TYMS and MTHFR polymorphisms, and individual 5FU CL. 


\section{MATERIALS AND METHODS}

\section{Patients and treatment}

A total of 130 consecutive B2 and C Duke's stage colorectal cancer patients on adjuvant therapy were prospectively studied between 1999 and 2008. Chemotherapeutic treatment consisted of the 5FU + leucovorin combination according to the Mayo administration schedule (O'Connel et al, 1997) (2 $\mathrm{min}$ i.v. bolus administration of $425 \mathrm{mg} \mathrm{m}^{-2} 5 \mathrm{FU}+20 \mathrm{mg} \mathrm{m}^{-2}$ folinic acid daily for 5 days, for 6 consecutive cycles every 4 weeks). The starting dose could be reduced by $25 \%$ in the oldest patients. If toxicity of grade $\geqslant 2$ occurred, the next doses were reduced by $25-50 \%$ or stopped, according to toxicity level. The study was approved by the Ethics Committee of the Azienda-ULSS 18 Rovigo, and all patients gave their written informed consent.

\section{Clinical evaluation}

Toxicity was recorded and graded according to World Health Organization (WHO) criteria and was dichotomously classified for statistical analysis in none-to-moderate (grade 0-2) and severe (grade 3-4).

The outcome variables were disease-free survival (DFS) and overall survival (OS). For DFS, an event was defined as the first occurrence of a tumour relapse that was not preceded by a second primary cancer. For OS, the outcome was death related to cancer and patients who died for other causes were treated as censored in survival analysis. The duration of follow-up was measured from the date of starting chemotherapy. Follow-up visits were scheduled every 3 months in the first year, every 6 months in the second and third years, and every year thereafter.

\section{Pharmacokinetic analysis}

5FU pharmacokinetics was determined on day 2 of the first therapy cycle, using an HPLC method and a limited sampling strategy described earlier (Gusella et al, 2002). Plasma concentration decay was analysed with a mono-exponential function, so that intercept (A) and slope (k) were obtained and used to calculate the main pharmacokinetic parameters:

- area under the plasma concentration-time curve: $\mathrm{AUC}=\mathrm{A} / \mathrm{k}$

- plasma clearance: $\mathrm{CL}=$ Dose/AUC.

With the limited sampling methods used, bias and accuracy for AUC estimate are 3.4 and 5.1\%, respectively (Gusella et al, 2002).

\section{Genetic analysis}

Genomic DNA was extracted from peripheral blood leukocytes with a commercial kit (Promega Corporation, Madison, WI, USA) and stored at $4{ }^{\circ} \mathrm{C}$ until genotyping. $0.2 \mu \mathrm{g}$ per sample of genomic DNA was used to carry out the PCR using specific primers in a $50 \mu \mathrm{l}$ final volume; genotyping was carried out according to earlier reported methods for TYMS 5'UTR VNTR and G $>$ C substitution (Gusella et al, 2006a), TYMS 3'UTR 6 bp insert-deletion (Ulrich et al, 2000), MTHFR C677T and MTHFR A1298C polymorphisms (Miao et al, 2002).

Repeat genotyping of a $10 \%$ random sample yielded a $100 \%$ agreement.

\section{Classification of TS expression based on combined $5^{\prime} \mathrm{UTR}$ and $3^{\prime}$ UTR genotypes}

Variable number of tandem repeats and G $>$ C SNP polymorphisms in the $5^{\prime}$ UTR were classified according to Kawakami and Watanabe (2003) in low expression $(2 \mathrm{R} / 2 \mathrm{R}, 2 \mathrm{R} / 3 \mathrm{RC}, 3 \mathrm{RC} / 3 \mathrm{RC})$ and highexpression TS genotypes (2R/3RG, 3RC/3RG, 3RG/3RG). 5'UTR and $3^{\prime}$ UTR were also combined in two different ways, based on the expected TS expression level (see Table 1). The simplest combination (combination A) takes into account VNTR and ins/del 3'UTR polymorphisms and classifies TS activity as 'high' or 'low', according to Hitre et al (2005). The more complex combination (combination B) also includes G $>$ C SNP in the $5^{\prime}$ UTR and divides TS activity into three expression groups: 'high', 'intermediate' and 'low'.

\section{Classification of MTHFR activity based on combined C677T and A1298C genotypes}

Similarly, MTHFR activity was classified as 'high', 'intermediate' and 'low', based on the expected MTHFR metabolic rate of the combined C677T and A1298C polymorphisms (Ulrich et al, 2002) (see Table 2).

\section{Statistical analysis}

Univariate logistic regression was used to identify the baseline prognostic factors related to toxicity. The factors significant at the 0.20 level were then introduced in a multivariate logistic regression

Table 2 MTHFR combined genotypes classified according to expected activity of metylenetetrahydrofolate reductase

\begin{tabular}{lllr}
\hline Activity level & MTHFR C677T & MTHFR A I298C & N \\
\hline High & $\mathrm{C} / \mathrm{C}$ & $\mathrm{A} / \mathrm{A}$ & 10 \\
Intermediate & $\mathrm{C} / \mathrm{C}$ & $\mathrm{C} / \mathrm{C}, \mathrm{A} / \mathrm{C}$ & 78 \\
& $\mathrm{~T} / \mathrm{T}, \mathrm{C} / \mathrm{T}$ & $\mathrm{A} / \mathrm{A}$ & \\
Low & $\mathrm{T} / \mathrm{T}, \mathrm{C} / \mathrm{T}$ & $\mathrm{C} / \mathrm{C}, \mathrm{A} / \mathrm{C}$ & 42 \\
\hline
\end{tabular}

Abbreviation: MTHFR = methylenetetrahydrofolate reductase .

Table I TYMS combined genotypes classified according to expected expression of thymidylate synthase

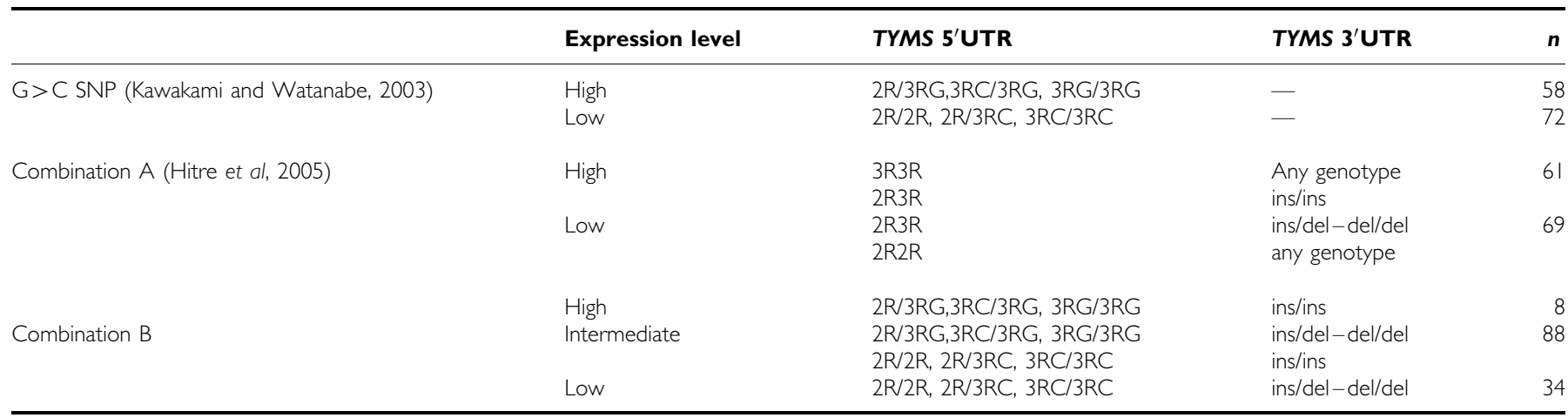

Abbreviations: SNP = single nucleotide polymorphism; UTR = untranslated region. 
model, and a backward-elimination approach was adopted. Interactions were tested at the 0.10 level of significance. The results are presented as odds ratio (OR) and 95\% confidence interval.

The hazard ratios (HRs) for disease recurrence and mortality, were estimated for individual covariates with the univariate Cox proportional-hazards model. Variables significant at the 0.20 level in the univariate analysis were entered into multivariate Cox proportional-hazards models in a backward selection procedure. Interactions were tested at the 0.10 level of significance. Proportionality assumption was tested including time-dependent covariates in the final model at a significance level of 0.10 . The results are presented as $\mathrm{HR}$ and $95 \%$ confidence interval. Covariates considered were age (two groups divided by the median value), sex, Dukes' stage (B2 and C), TYMS VNTR polymorphism (three genotypes), TYMS G $>$ C SNP polymorphism (low- and high-expression genotypes), TYMS ins/del polymorphism (three genotypes), TYMS 5'UTR and $3^{\prime}$ UTR combined genotypes (combination A: two groups; combination B: three groups; see Table 1), MTHFR C677T polymorphism (three genotypes), MTHFR A1298C polymorphism (three genotypes), MTHFR 677 and 1298 combined genotypes (three groups; see Table 2), 5FU clearance per Kg (two groups divided by median value) and true cumulative 5FU dose administered, expressed as a percentage of the theoretical dose (continuous).

Survival curves were estimated using the Kaplan-Meier method and differences between individual curves were assessed by logrank test. Data are presented as means \pm s.d., unless otherwise specified. The $\chi^{2}$-test and $t$-test for unpaired data were applied to compare frequencies and means, respectively. A one-way ANOVA (followed by the post-hoc linear-trend test, when needed) was used to compare groups. All tests were two-sided with a 5\% significance level. Data were analysed with version 9.1.3 of SAS software for Windows (SAS Institute Inc., Cary, NC, USA).

Hardy-Weinberg equilibrium and linkage disequilibrium were evaluated by PyPop on line free software (University of California, Berkley, USA) (Lancaster et al, 2003).

\section{RESULTS}

\section{Clinical data}

A total of 130 patients (46 women and 84 men) were the study population. All had a Karnofsky performance status score between 100 and 80. Mean age was $63.7 \pm 10.3$, ranging from 34 to 84 years. The primary tumour site was right colon in 47 cases and left colon in 83 cases. Duke's tumour stage was B2 in 51 patients and C in 79 patients. Stage $C$ was more frequently found in patients aged $\geqslant 65$ years than in those aged $<65$ (80.3 vs $42.2 \%$; $P<0.0001)$.

A total of 116 patients were treated for all six planned cycles; 10 patients stopped the treatment prematurely because of toxicity, mainly at the first or second cycle, and four patients stopped because of disease progression. The true cumulative dose was, on average, $74.1 \pm 20.2 \%$ (range: $14.4-101.6 \%$ ) of the theoretical one, and dose reduction was significantly greater in patients aged $\geqslant 65$ $(30.5 \pm 19.0 \%)$ than $<65(21.1 \pm 20.5 \%)(P<0.0075)$.

During chemotherapy, $45(35 \%)$ patients suffered from grade $3-$ 4 toxicity, mainly mucositis $(28 \%)$, diarrhea (10\%) and neutropenia (8\%). During follow-up (median 3.8 years, range $0.4-8.5$ years), 44 patients had documented recurrent disease and 31 died, three for non cancer-related causes. Overall survival rates were $87.6 \%$ at 3 years and $73.5 \%$ at 5 years. The 3 - and 5 -year DFS rates were 69.8 and $62.2 \%$, respectively.

\section{Pharmacokinetic data}

The mean 5FU starting dose was $724.5 \pm 88.2 \mathrm{mg}$ (range: $350-920 \mathrm{mg}$ ) and the related pharmacokinetic parameters were broadly variable among patients (AUC range: $146-1236 \mathrm{mgl}^{-1} \times \mathrm{min}$; CL range: $0.0084-0.07051 \mathrm{~min}^{-1} \mathrm{Kg}^{-1}$ ). 5FU clearance measured at the first cycle was inversely correlated with the percent dose reduction during the following cycles: the lower the CL, the greater the reduction in the cumulative dose, with a linear trend across the CL quartiles (ANOVA, $P<0.0001$; linear trend, $P<0.0001$ ) (Figure 1).

\section{Genetic data}

The frequency of TYMS and MTHFR genotypes found in our population was similar to that reported earlier in white populations, and allelic distributions were in Hardy-Weinberg equilibrium. Strong-linkage disequilibrium was found for $5^{\prime}$ UTR VNTR and $3^{\prime} \mathrm{UTR}$ polymorphisms $\left(d^{\prime}=0.81 ; P<0.0001\right), 5^{\prime} \mathrm{UTR} \mathrm{G}>\mathrm{C}$ and $3^{\prime}$ UTR polymorphisms $\left(d^{\prime}=0.52 ; P<0.0001\right)$ and MTHFR C677T and A1298C polymorphisms $\left(d^{\prime}=0.96, P<0.0001\right)$. TYMS and MTHFR genotype distributions were not significantly different between stages B2 and C, males and females, patients aged $<65$ and $\geqslant 65$ years.

\section{Toxicity analysis}

Univariate analysis showed that low-5FU CL had a highly significant effect on severe toxicity $(P<0.0001)$. Among the other variables, only age was marginally significant $(P=0.059)$ (Table 3$)$. Multivariate analysis confirmed low-5FU CL $(P<0.0001)$ as an independent prognostic factor for grade 3-4 toxicity $(\mathrm{OR}=7.32$, 95\% CI: $3.06-17.51, P<0.0001)$; in addition, the 'high-activity' MTHFR 677 CC genotype proved to be associated with a reduced risk of side-effects (T/T vs $\mathrm{C} / \mathrm{C} \mathrm{OR}=1.17,95 \% \mathrm{CI}$ : $0.34-4.08$; $\mathrm{C} / \mathrm{T}$ vs $\mathrm{C} / \mathrm{C} \mathrm{OR}=3.10,95 \% \mathrm{CI}: 1.21-7.94, P=0.040)$. When specific toxicity type was considered, severe mucositis was predicted only by low 5FU CL $(\mathrm{OR}=7.92,95 \% \mathrm{CI}: 3.00-20.91, P<0.0001)$, whereas no variable predicted diarrhea and neutropenia.

\section{Survival analysis}

Survival analysis was restricted to the 122 patients who completed at least three chemotherapy cycles, that is, those who received at least $50 \%$ of the planned cumulative dose, in order to exclude the patients whose clinical outcome could not be reasonably ascribed to $5 \mathrm{FU}$ treatment. Univariate analysis showed that advanced age and Dukes' stage $\mathrm{C}$ had a significant negative prognostic effect on

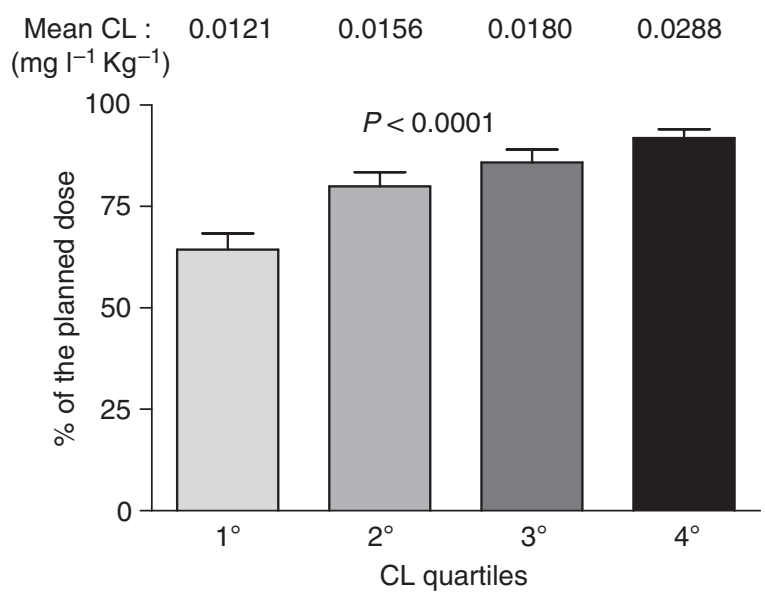

Figure I Mean cumulative 5FU dose administered, as percentage of initially planned dose, in each 5FU clearance quartile. Bars represent standard errors. Four patients who stopped therapy because of disease progression were excluded from analysis. 
Table 3 Univariate logistic regression of toxicity in 130 patients adjuvantly treated with 5FU chemotherapy

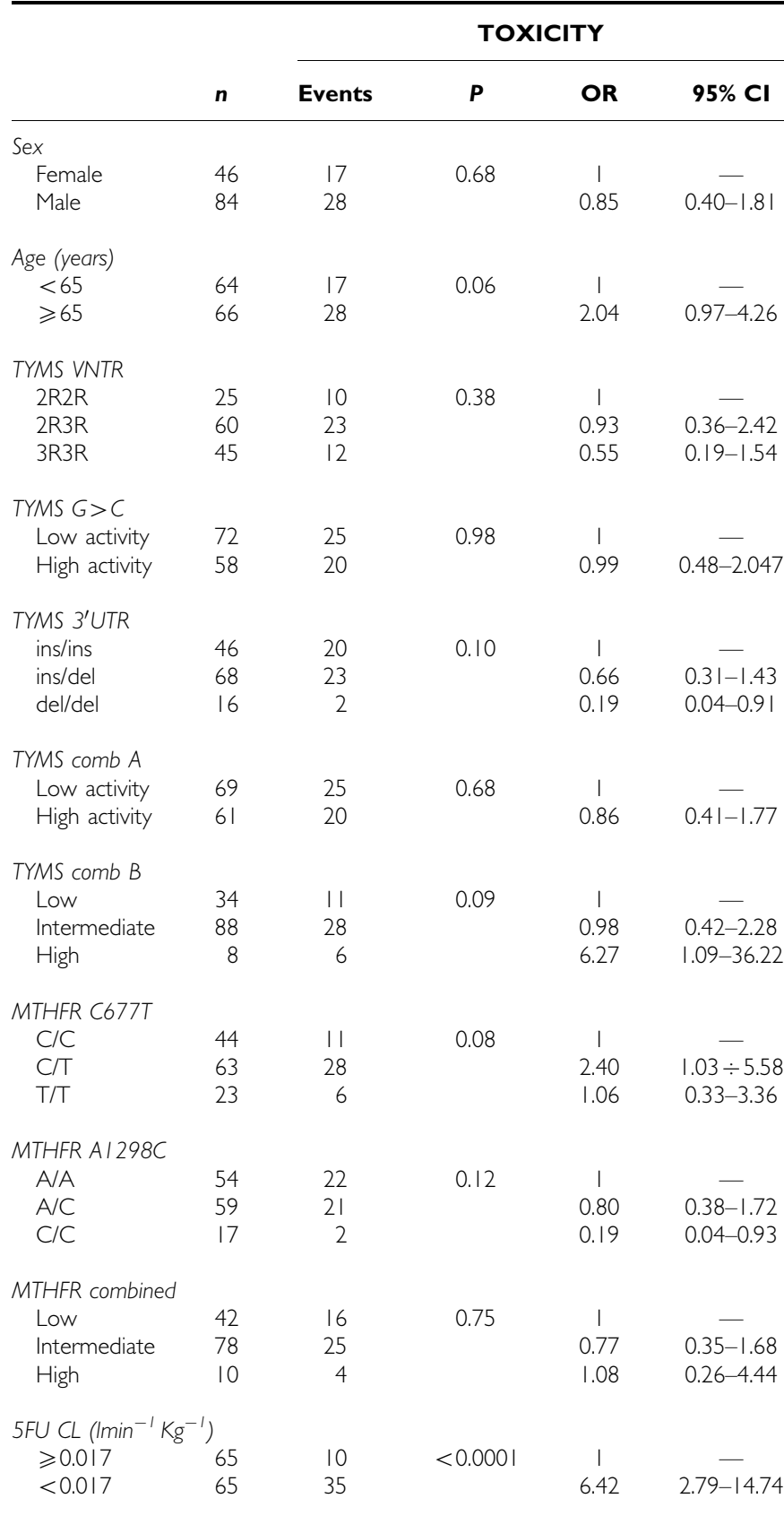

Abbreviations: $\mathrm{Cl}=$ confidence interval; $\mathrm{CL}=$ plasma clearance; $\mathrm{MTHFR}=$ methylenetetrahydrofolate reductase; $\mathrm{OR}=$ odds ratio; UTR $=$ untranslated region; VNTR = variable number tandem repeats.

DFS, and that high-5FU CL was significantly related with a worse OS (Table 4). Conversely, sex, cumulative dose reduction and onset of severe toxicity had no predictive value. Also, no significant association was observed between DFS or OS and any TYMS or MTHFR polymorphisms, either analysed separately or in combination.

In the multivariate Cox-regression model, advanced age and high-5FU clearance proved to be unfavourable prognostic factors for both DFS and OS. An age $\geqslant 65$ was associated with an HR of 3.34 for relapsing (95\% CI: $1.65-6.75 ; P=0.0008)$ and 2.66 for dying $(95 \% \quad$ CI: $1.32-8.64 ; \quad P=0.024)$. Patients with $\quad \mathrm{CL}$ $\geqslant 0.0171 \mathrm{~min}^{-1} \mathrm{Kg}^{-1}$ had a cancer-related death risk 3.37 times higher (95\% CI: $1.32-8.64 ; P=0.011)$ and a disease-recurrence risk 1.96 times higher (95\% CI: $1.03-3.73 ; P=0.041)$ than patients with $\mathrm{CL}<0.0171 \mathrm{~min}^{-1} \mathrm{Kg}^{-1}$.

When patients were stratified according to CL and age in four groups (Figure 2 ), those with high $\mathrm{CL}$ and aged $\geqslant 65$ survived less (HR: 6.50; 95\% CI: $1.44-29.36 ; P=0.015)$ and relapsed earlier (HR: 5.99; 95\% CI: $1.95-18.51 ; P=0.0018)$ than those with low CL and aged $<65$, who had the best outcome.

A significant difference in DFS was also observed between old/high CL and young/high CL patients (log-rank test: $P=0.025)$ and between old/low CL and young/low CL patients $(P=0.047)$. In addition, $O S$ of patients aged $>65$ and with high CL was significantly worse than that of any other group ( $P$ range: $0.012-0.009$ ). The comparisons between the other groups did not reach the significance level.

Frequency of Duke's C stage was lower in the younger/low CL group than in the older/high CL group (42.3 vs $81.5 \%, P=0.0033$ ), whereas severe toxicity was more frequent in the former group than in the latter $(42.3$ vs $18.5 \%, P=0.059)$. Nevertheless, as stated above, in the overall population neither C Duke's stage nor severe toxicity were markers of OS/DFS, as their predictive value in the multivariate analysis was probably included in age and $C L$, respectively.

\section{DISCUSSION}

The main clinical implication emerging from our study is that high-5FU CL $\left(\geqslant 0.0171 \mathrm{~min}^{-1} \mathrm{Kg}^{-1}\right)$, measured at the beginning of the adjuvant chemotherapy course in colorectal patients, is the strongest single predictor of reduced toxicity and poor clinical outcome in terms of both DFS and OS. Multivariate analysis also showed that age $\geqslant 65$ was associated with shorter DFS and OS but not with more severe toxicity, suggesting that preventive dose reduction in elderly patients is not advisable. As a whole, the association of high-5FU CL with advanced age had the worse prognostic meaning for both DFS and OS. Furthermore, patients homozygous C/C for C677T MTHFR, who are presumed to havehigh enzyme activity, had a lower-toxicity risk.

With respect to 5FU tolerability, our findings are in good agreement with earlier literature data, as high AUC or low CL have invariably been associated with more severe $5 \mathrm{FU}$ toxicity after any administration schedule (Young et al, 1999; Di Paolo et al, 2002; Jansman et al, 2002; Ychou et al, 2003; Codacci-Pisanelli et al, 2005; Gusella et al, 2006b; Capitain et al, 2008). A recent, large, prospective trial (Schwab et al, 2008) on cancer patients treated with 5FU monotherapy confirmed a significant--although weak--link between mutant MTHFR C677T genotypes and FU toxicity but, at odds with our results, also found a significant correlation with the $2 \mathrm{R} / 2 \mathrm{R}$ TYMS genotype. A correlation between 5FU toxicity and the VNTR TYMS polymorphism has also been reported by Lecomte et al (2004) and Pullarkat et al (2001), who found less toxicity in patients with the $3 \mathrm{R} / 3 \mathrm{R}$ genotype. Indeed, our univariate analysis also suggests a non-significant trend toward a decreased toxicity risk in patients carrying the $3 R / 3 R$ genotype in comparison with carriers of the $2 \mathrm{R} / 2 \mathrm{R}$ TYMS genotype $(\mathrm{OR}=0.55)$. A significant correlation with C677T MTHFR genotype, but not with TYMS genotypes, was also found by Sharma et al (2008) in colorectal patients treated with capecitabine, a $5 \mathrm{FU}$ prodrug.

With respect to factors correlated with therapeutic outcomes, age and 5FU CL turned out to be the only significant predictors of DFS and OS in our study. The association between age and clinical outcome may be partly explained by the greater prevalence of stage $\mathrm{C}$ in our older patients. However, other studies found that advanced age is an independent risk factor (Gill et al, 2004; Schippinger et al, 2007). Similarly, an association between low 5FU 
Table 4 Univariate Cox regression of disease free and overall survival in the 122 patients adjuvantly treated with $5 F U$ chemotherapy for at least three cycles

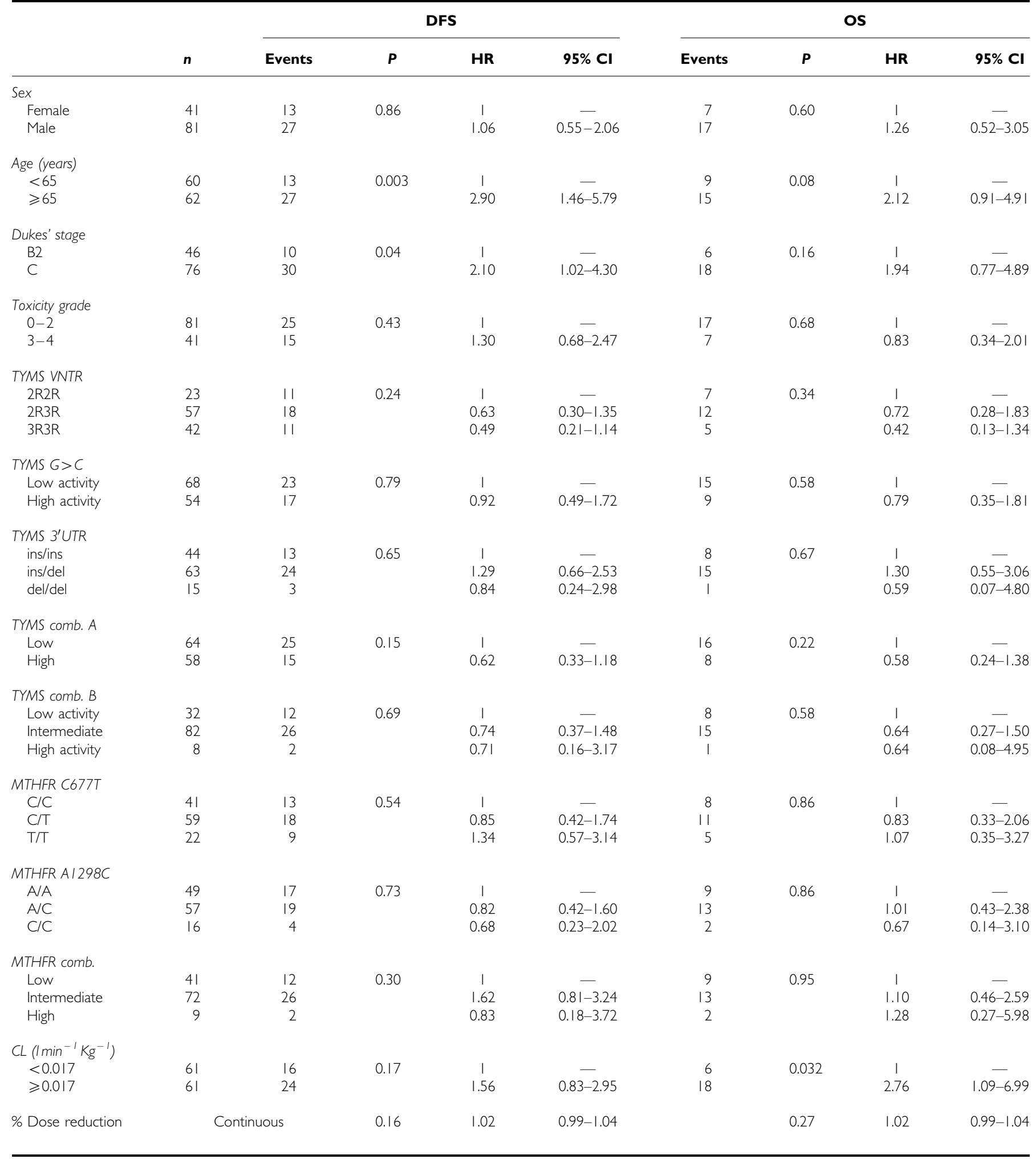

Abbreviations: $\mathrm{Cl}=$ confidence interval; $\mathrm{CL}=$ plasma clearance; $\mathrm{DFS}=$ disease-free survival; $\mathrm{HR}=$ hazard ratio; $M T H F R=$ methylenetetrahydrofolate reductase; $\mathrm{OS}=$ overall survival; UTR = untranslated region; VNTR $=$ variable number tandem repeats.

CL or high AUC and improved 5FU response has already been reported in cancer patients treated with either continuous 5FU infusion (Milano et al, 1994; Gamelin et al, 1996) or Machover's bolus administration schedule (Di Paolo et al, 2008).
DPD governs 5FU catabolism in both normal and tumour cells, and a significant correlation has been shown between DPD expression in colorectal tumours and the surrounding intestinal mucosa (Tanaka-Nozaki et al, 2001; Amatori et al, 2006). Thus, on 

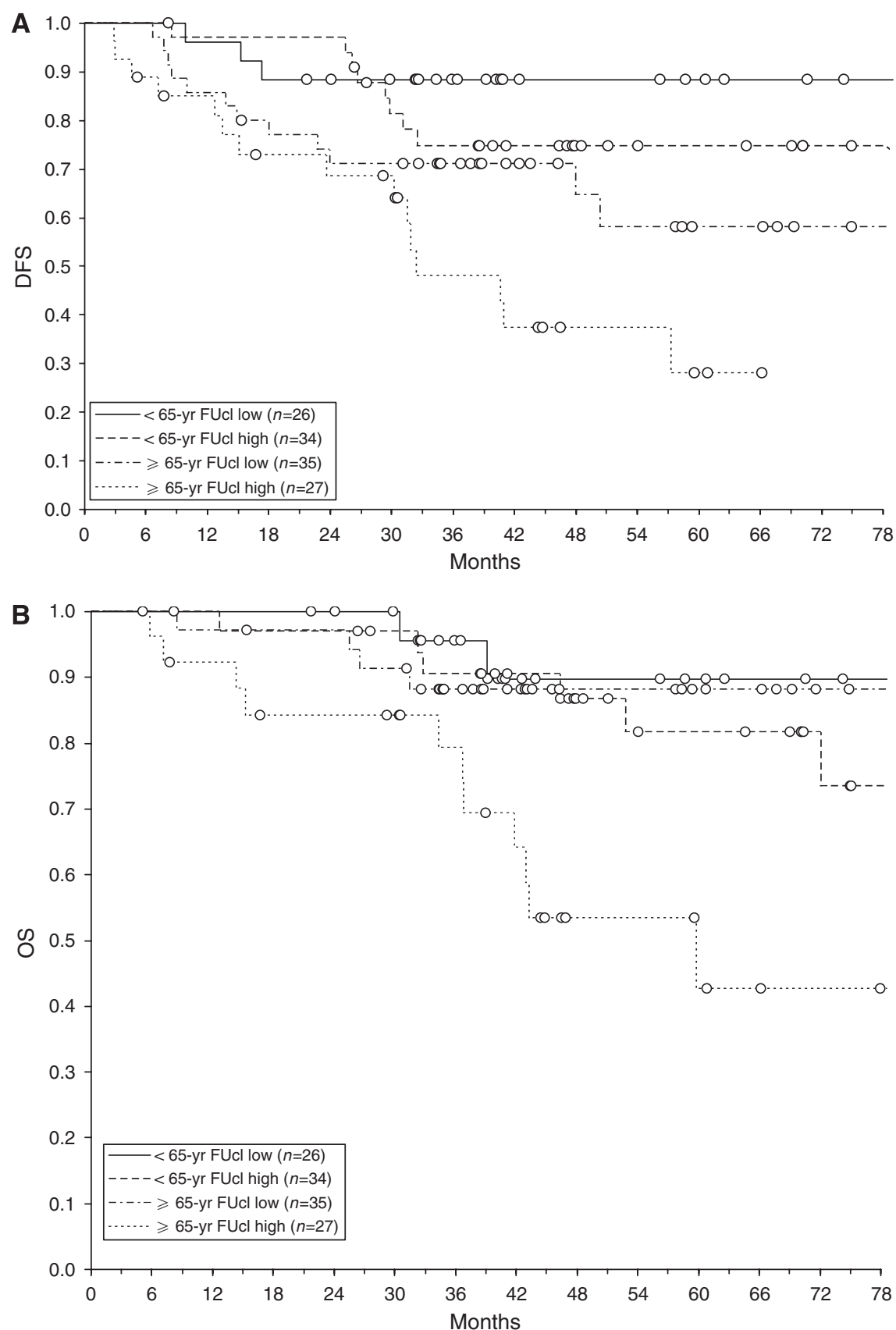

Figure 2 Disease-free $(\mathbf{A})$ and overall survival $(O S)$ plots $(\mathbf{B})$ of patients stratified in four groups according to age $(<$ or $\geqslant 65$ years $)$ and $5 \mathrm{FU}$ clearance $\left(<\right.$ or $\left.\geqslant 0.017 \mathrm{mg} \mathrm{I}^{-1} \mathrm{Kg}^{-1}\right)$. Open circles indicate censored data points. Log-rank test was significant for both disease-free survival $(D F S)(P=0.00 । 2)$ and overall survival $(\mathrm{OS})(P=0.0036)$.

the one hand, a low-5FU CL may improve 5FU delivery to the tumour and, on the other, decrease 5FU inactivation inside it. In line with this view, several studies in colorectal cancer patients treated with 5FU-based adjuvant therapy have shown that lowDPD protein or mRNA expression in the tumour is associated with longer DFS and OS (Popat et al, 2004; Ciaparrone et al, 2006; Jensen et al, 2006; Lassmann et al, 2006; Popat et al, 2006; Yamada et al, 2008), whereas no consistent correlation has been shown with TS tumour expression (Kamoshida et al, 2004; Aguiar et al, 2005; Ciaparrone et al, 2006; Jensen et al, 2006; Lassmann et al, 2006; Popat et al, 2006; Soong et al, 2008; Yamada et al, 2008). Indeed, in our study, none of the three TS polymorphisms, considered alone or in combination (VNTR, G $>\mathrm{C}$ substitution, $6 \mathrm{bp}$ insertiondeletion), could predict the clinical outcome. This negative results may be because of an insufficient power of our study to detect genetic associations or to some inaccuracy in grouping the genotypes. However, our population size was comparable with that of other similar studies and genotype classifications reflected the best available information on gene biological activity. In this respect, literature data are inconclusive in that the same TS polymorphisms have been correlated with both favourable and unfavourable effects, and no correlation has even been reported (Dotor et al, 2006; Gusella and Padrini, 2007; Gosens et al, 2008; Fernandez-Contreras et al, 2009). Besides the methodological 
differences between clinical trials, a number of biological factors may have obscured the link between TYMS polymorphisms and 5FU activity. First, it is known that 5FU can not only inhibit TS but also affect mRNA function. Sobrero et al (1997) have suggested, and others (Kubota et al, 2002; Matsusaka et al, 2003; Hoshino et al, 2005) have experimentally confirmed, that $5 \mathrm{FU}$ incorporation into colorectal tumour mRNA is significantly greater after bolus than after continuous infusion. If this is true, RNA-mediated effects may prevail over TS inhibition, and TS expression may play only an ancillary role in the antitumour activity of 5FU bolus administration. Second, translation of TS mRNA is inhibited by TS protein in an autoregulatory manner (Chu et al, 1991), so that the influence of gene polymorphisms may be blunted. Third, it has been reported that $5 \mathrm{FU}$ treatment can induce a variable, compensatory increase in TS mRNA levels in colorectal tumours (Ukida et al, 2001; Tanaka-Nozaki et al, 2003) and that patients with no or minor mRNA increase show a better response to therapy (Ukida et al, 2001). Fourth, the $5^{\prime}$-UTR polymorphism is in linkage disequilibrium with the $3^{\prime}$-UTR polymorphism, in that the $+6 /+6 \mathrm{bp}$ and $-6 /-6 \mathrm{bp}$ genotypes are associated with $2 \mathrm{R} / 2 \mathrm{R}$ and 3R/3R genotypes, respectively (Mandola et al, 2004). It is therefore likely that the coexistence in the same gene of high- and low-expression genotypes may attenuate functional consequences. Fifth, TS tumour levels may be simultaneously markers of tumour aggressiveness and tumour sensitivity to 5FU. In this regard, a recent, large study (Soong et al, 2008) reported that low-TS expression was correlated with worse prognosis in colorectal patients treated with surgery alone whereas no significant effect on survival was noted in the 5FU-treated group. As it is generally acknowledged that low TS-expressing tumours are more sensitive to 5FU (Gusella and Padrini, 2007), the lack of prognostic

\section{REFERENCES}

Aguiar Jr S, Lopes A, Soares FA, Rossi BM, Ferreira FO, Nakagawa WT, Carvalho AL, Filho WJ (2005) Prognostic and predictive value of the thymidylate synthase expression in patients with non-metastatic colorectal cancer. Eur J Surg Oncol 31: 863-868

Amatori F, Di Paolo A, Del Tacca M, Fontanini G, Vannozzi F, Boldrini L, Bocci G, Lastella M, Danesi R (2006) Thymidylate synthase, dihydropyrimidine dehydrogenase and thymidine phosphorylase expression in colorectal cancer and normal mucosa in patients. Pharmacogenet Genomics 16: $809-816$

Board RE, Valle JW (2007) Metastatic colorectal cancer: current systemic treatment options. Drugs 67: $1851-1867$

Capitain O, Boisdron-Celle M, Poirier AL, Abadie-Lacourtoisie S, Morel A, Gamelin E (2008) The influence of fluorouracil outcome parameters on tolerance and efficacy in patients with advanced colorectal cancer. Pharmacogenomics J 8: 256-267

Chu E, Koeller DM, Casey JL, Drake JC, Chabner BA, Elwood PC, Zinn S, Allegra CJ (1991) Autoregulation of human thymidylate synthase messenger RNA translation by thymidylate synthase. Proc Natl Acad Sci USA 88: 8977 - 8981

Chung HY, Saltz LB (2007) Adjuvant therapy of colon cancer: current status and future directions. Cancer J 13: $192-197$

Ciaparrone M, Quirino M, Schinzari G, Zannoni G, Corsi DC, Vecchio FM, Cassano A, La Torre G, Barone C (2006) Predictive role of thymidylate synthase, dihydropyridine dehydrogenase and thymidine phosphorylase expression in colorectal cancer patients receiving adjuvant 5-fluorouracil. Oncology 70: $366-377$

Codacci-Pisanelli G, Pinedo HM, Lankelma J, Van Groeningen CJ, Van Kuilenburg AB, Van Gennip AH, Peters GJ (2005) Pharmacokinetics of bolus 5-fluorouracil: relationship between dose, plasma concentrations, area-under-the-curve and toxicity. J Chemother 17: 315-320

Cohen V, Panet-Raymond V, Sabbaghian N, Morin I, Batist G, Rozen R (2003) Methylenetetrahydrofolate reductase polymorphism in advanced colorectal cancer: a novel genomic predictor of clinical response to fluoropyrimidine-based chemotherapy. Clin Cancer Res 9: $1611-1615$ significance of low TS levels in 5FU-treated patients may be explained by a concomitant harmful effect on tumour growth.

The prognostic role of the MTHFR polymorphism in the response to 5FU did not emerge from our study. No studies with adjuvant therapy are available for a comparison, although contradictory results come from studies in other clinical settings (Cohen et al, 2003; Etienne et al, 2004; Jakobsen et al, 2005; Terrazzino et al, 2006; Ruzzo et al, 2007; Zhang et al, 2007). The reasons for such discrepancies are unclear.

In conclusion, our study makes a contribution to the controversial issue of which colorectal patients are more likely to gain benefit from 5FU adjuvant chemotherapy. One strength of our investigation is the simultaneous evaluation of an index of drug exposure (5FU CL) and of several TYMS and MTHFR polymorphisms possibly related to tumour sensitivity, in a group of patients homogeneously treated with a repeated bolus regimen. The finding that patients' demographic and pharmacokinetic characteristics are more predictive of clinical outcome than some putative genetic markers suggests that the traditional, phenotypic approach to clinical cancer research should not be abandoned and that the genetic approach requires further work to prove its clinical usefulness. Feasibility and utility of a pharmacokinetic test to assess 5FU CL in colorectal patients starting adjuvant therapy need to be evaluated in a prospective trial.

\section{ACKNOWLEDGEMENTS}

This research was supported by grants from Regione Veneto (ricerca finalizzata 934/02/99), AIRC Veneto (2005-2007).
Di Paolo A, Ibrahim T, Danesi R, Maltoni M, Vannozzi F, Flamini E, Zoli W, Amadori D, Del Tacca M (2002) Relationship between plasma concentrations of 5-fluorouracil and 5-fluoro-5,6-dihydrouracil and toxicity of 5-fluorouracil infusion in cancer patients. Ther Drug Monit 24: $588-593$

Di Paolo A, Lencioni M, Amatori F, Di Donato S, Bocci G, Orlandini C, Lastella M, Federici F, Iannopollo M, Falcone A, Ricci S, Del Tacca M, Danesi R (2008) 5-fluorouracil pharmacokinetics predicts diseasefree survival in patients administered adjuvant chemotherapy for colorectal cancer. Clin Cancer Res 14: 2749-2755

Dotor E, Cuatrecases M, Martines-Iniesta M, Navarro M, Vilardell F, Guinò E, Pareja L, Figueras A, Mollevì DG, Serrano T, de Oca J, Peinado MA, Moreno V, Germà JR, Capellà G, Villanueva A (2006) Tumor thymidylate synthase 1494del6 genotype as a prognostic factor in colorectal cancer patients receiving fluorouracil-based adjuvant treatment. J Clin Oncol 24: $1603-1611$

Etienne MC, Formento JL, Chazal M, Francoual M, Magné N, Formento P, Bourgeon A, Seitz JF, Delpero JR, Letoublon C, Pezet D, Milano G (2004) Methylenetetrahydrofolate reductase gene polymorphisms and response to fluorouracil-based treatment in advanced colorectal cancer patients. Pharmacogenetics 14: 785-792

Fernandez-Contreras ME, Sanchez-Hernadez JJ, Gonzalez E, Herraez B, Dominguez I, Lozano M, Garcia de Paredes ML, Muñoz A, Gamallo C (2009) Combination of polymorphisms within $5^{\prime}$ and $3^{\prime}$ untranslated regions of thymidylate synthase gene modulates survival in 5 fluorouracil-treated colorectal cancer patients. Int J Oncol 34: 219-229

Gamelin EC, Danquechin-Dorval EM, Dumesnil YF, Maillart PJ, Goudier MJ, Burtin PC, Delva RG, Lortholary AH, Gesta PH, Larra FG (1996) Relationship between 5-fluorouracil (5-FU) dose intensity and therapeutic response in patients with advanced colorectal cancer receiving infusional therapy containing 5-FU. Cancer 77: 441-451

Gill S, Loprinzi CL, Sargent DJ, Thomé SD, Alberts SR, Haller DG, Benedetti J, Francini G, Shepherd LE, Francois Seitz J, Labianca R, Chen W, Cha SS, Heldebrant MP, Goldberg RM (2004) Pooled analysis of fluorouracil-based adjuvant therapy for stage II and III 
colon cancer: Who benefits and by how much? J Clin Oncol 22: $1797-1806$

Gosens MJ, Moerland E, Lemmens VP, Rutten HT, Tan-Go I, van den Brule AJ (2008) Thymidylate synthase genotyping is more predictive for therapy response than immunohistochemistry in patients with colon cancer. Int J Cancer 123: 1941 - 1949

Gusella M, Bolzonella C, Crepaldi G, Ferrazzi E, Padrini R (2006a) A novel G/C single-nucleotide polymorphism in the double 28-bp repeat thymidylate synthase allele. Pharmacogenomics $J$ 6: $421-424$

Gusella M, Crepaldi G, Barile C, Bononi A, Menon D, Toso S, Scapoli D, Stivano L, Ferrazzi E, Grigoletto F, Ferrari M, Padrini R (2006b) Pharmacokinetic and demographic markers of 5-fluoruracil toxicity in 181 patients on adjuvant therapy for colorectal cancer. Ann Oncol 17: $1656-1660$

Gusella M, Ferrazzi E, Ferrari M, Padrini R (2002) New limited sampling strategy for determining 5-fluorouracil area under the concentrationtime curve after rapid intravenous bolus. Ther Drug Monit 24: 425-431

Gusella M, Padrini R (2007) G > C SNP of thymidylate synthase with respect to colorectal cancer. Pharmacogenomics 8: $985-996$

Hitre E, Budai B, Adleff V, Czeglédi F, Horváth Z, Gyergyay F, Lövey J, Kovács T, Orosz Z, Láng I, Kásler M, Kralovánszky J (2005) Influence of thymidylate synthase gene polymorphisms on the survival of colorectal cancer patients receiving adjuvant 5-fluorouracil. Pharmacogenet Genomics 15: $723-730$

Hoshino S, Yamashita Y, Maekawa T, Shirakusa T (2005) Effects on DNA and RNA after the administration of two different schedules of 5fluorouracil in colorectal cancer patients. Cancer Chemother Pharmacol 56: $648-652$

Jakobsen A, Nielsen JN, Gyldenkerne N, Lindeberg J (2005) Thymidylate synthase and methylenetetrahydrofolate reductase gene polymorphism in normal tissue as predictors of fluorouracil sensitivity. J Clin Oncol 23: $1365-1369$

Jansman FGA, Coenen JLLM, De Graaf JC, Tobi H, Sleijfer DT, Brouwers JR (2002) Relationship between pharmacokinetics of 5-FU in plasma and in saliva, and toxicity of 5-fluorouracil/folinic acid. Anticancer Res 22: $3449-3456$

Jensen SA, Vainer B, Sørensen JB (2006) The prognostic significance of thymidylate synthase and dihydropyridine dehydrogenase in colorectal cancer of 303 patients adjuvantly treated with 5-fluorouracil. Int J Cancer 120: $694-701$

Kamoshida S, Matsuoka H, Ishikawa T, Maeda K, Shimomura R, Inada K, Tsutsumi Y (2004) Immunohistochemical evaluation of thymidylate synthase (TS) and $\mathrm{p} 16^{\mathrm{INK} 4 \mathrm{a}}$ in advanced colorectal cancer: implication of TS expression in 5-FU-based adjuvant chemotherapy. Jpn J Clin Oncol 34: $594-601$

Kawakami K, Salonga D, Park JM (2001) Different length of a polymorphic repeat sequence in the thymidylate synthase gene affects translational efficiency but not its gene expression. Clin Cancer Res 7: 4096-4101

Kawakami K, Watanabe G (2003) Identification and functional analysis of single nucleotide polymorphism in the tandem repeat sequence of thymidylate synthase gene. Cancer Res 63: 6004-6007

Kubota T, Watanabe M, Otani Y, Kitajima M, Fukushiuma M (2002) Different pathways of 5-fluorouracil metabolism after continuous venous or bolus injection in patients with colon carcinoma: possible predictive value of thymidylate synthetase mRNA and ribonucleotide reductase for 5-fluorouracil sensitivity. Anticancer Res 22: 3537-3540

Lancaster A, Nelson MP, Single RM, Meyer D, Thomson G (2003) PyPop: a software framework for population genomics: analyzing large-scale multi-locus genotype data. In Pacific Symposium on Biocomputing 8, Altman RB et al (ed) pp 514-525. World Scientific: Singapore

Lassmann S, Henning M, Rosenberg R, Nährig J, Schreglmann J, Krause F, Poignee-Heger M, Nekarda H, Höfler H, Werner M (2006) Thymidine phosphorylase, dihydropyridine dehydrogenase and thymidylate synthase mRNA expression in primary colorectal tumors - correlation to tumor histopathology and clinical follow-up. Int J Colorectal Dis 21: $238-247$

Lecomte T, Ferraz JM, Zinzindohoue F, Loriot MA, Tregouet DA, Landi B, Berger A, Cugnenc PH, Jian R, Beaune P, Laurent-Puig P (2004) Thymidylate synthase gene polymorphism predicts toxicity in colorectal cancer patients receiving 5-fluorouracil-based chemotherapy. Clin Cancer Res 10: $5880-5888$

Mandola MV, Stoehlmacher J, Muller-Weeks S, Cesarone G, Yu MC, Lenz HJ, Ladner RD (2003) A novel single nucleotide polymorphism within the $5^{\prime}$ tandem repeat polymorphism of the thymidylate synthase gene abolishes USF-1 binding and alters transcriptional activity. Cancer Res 63: $2898-2904$

Mandola MV, Stoehlmacher J, Zhang W, Groshen S, Yu MC, Iqbal S, Lenz HJ, Ladner RD (2004) A 6 bp polymorphism in the thymidylate synthase gene causes message instability and is associated with decreased intratumor TS mRNA levels. Pharmacogenetics 14: 319-327

Matsusaka S, Yamasaki H, Kitayama Y, Okada T, Maeda S (2003) Differential effects of two fluorouracil administration regimens for colorectal cancer. Oncol Rep 10: 109-113

Miao X, Xing D, Tan W, Qi J, Lu W, Lin D (2002) Susceptibility to gastric cardia adenocarcinoma and genetic polymorphism in methylenetetrahydrofolate reductase in an at-risk Chinese population. Cancer Epidemiol Biomarkers and Prev 11: $1454-1458$

Milano G, Etienne MC, Renee N, Thyss A, Schneider M, Ramaioli A, Demard F (1994) Relationship between fluorouracil systemic exposure and tumor response and patient survival. J Clin Oncol 12: 1291-1295

O'Connel MJ, Mailliard JA, Kahn MJ, Macdonald JS, Haller DG, Mayer RJ, Wieand HS (1997) Controlled trial of fluorouracil and low-dose leucovorin given for 6 months as postoperative adjuvant therapy for colon cancer. J Clin Oncol 15: 246-250

Pinedo HM, Peters GF (1988) Fluorouracil: biochemistry and pharmacology. J Clin Oncol 6: 1653-1664

Popat S, Chen Z, Zhao D, Pan H, Hearle N, Chandler I, Shao Y, Aherne W, Houlston R (2006) A prospective, blinded analysis of thymidylate synthase and p53 expression as prognostic markers in the adjuvant treatment of colorectal cancer. Ann Oncol 17: 1810-1817

Popat S, Matakidou A, Houlston RS (2004) Thymidylate synthase expression and prognosis in colorectal cancer: a systematic review and meta-analysis. J Clin Oncol 22: 529-536

Pullarkat ST, Stoehlmacher J, Ghaderi V, Xiong YP, Ingles SA, Sherrod A, Warren R, Tsao-Wei D, Groshen S, Lenz HJ (2001) Thymidylate synthase gene polymorphism determines response and toxicity of 5-FU chemotherapy. Pharmacogenomics J 1: $65-70$

Robien K, Boyton A, Ulrich CM (2005) Pharmacogenetics of folate-related drug targets in cancer treatment. Pharmacogenomics 6: 673-689

Ruzzo A, Graziano F, Loupakis F, Rulli E, Canestrari E, Santini D, Catalano V, Ficarelli R, Maltese P, Bisonni R, Masi G, Schiavon G, Giordani P, Giustini L, Falcone A, Tonini G, Silva R, Mattioli R, Floriani I, Magnani M (2007) Pharmacogenetic profiling in patients with advanced colorectal cancer treated with first-line POLFOX-4 chemotherapy. J Clin Oncol 25: $1247-1254$

Sharma R, Hoskins JM, Rivory LP, Zucknick M, London R, Liddle C, Clarke SJ (2008) Thymidylate synthase and methylenetetrahydrofolate reductase gene polymorphisms and toxicity to capecitabine in advanced colorectal cancer patients. Clin Cancer Res 14: 817-825

Schippinger W, Samonigg H, Schlaberl-Moser R, Greil R, Thödtmann R, Tschmelitsch J, Jagoditsch M, Steger GG, Jakesz R, Herbst F, Hofbauer F, Rabl H, Wohlmuth P, Gnant M, Thaler J (2007) A prospective randomized phase III trial of adjuvant chemotherapy with 5-fluorouracil and leucovorin in patients with stage II colon cancer. Br J Cancer 97: $1021-1027$

Schwab M, Zanger UM, Marx C, Schaeffeler E, Klein K, Dippon J, Kerb R, Blievernicht J, Fischer J, Hofmann U, Bokemeyer C, Eichelbaum M (2008) Role of genetic and nongenetic factors for fluorouracil treatmentrelated severe toxicity: prospective clinical trial by the German 5-FU toxicity group. J Clin Oncol 26: $2131-2138$

Scott J, Weir D (1994) Folate/vitamin B12 inter-relationship. Essays Biochem 28: $63-72$

Sobrero F, Aschele C, Bertino JR (1997) Fluorouracil in colorectal cancer a tale of two drugs: implications for biochemical modulation. J Clin Oncol 15: 368-381

Soong R, Shah N, Salto-Tellez M, Tai BC, Soo RA, Han HC, Ng SS, Tan WL, Zeps N, Joseph D, Diasio RB, Iacopetta B (2008) Prognostic significance of thymidylate synthase, dihydropyridine dehydrogenase and thymidine phosphorylase protein expression in colorectal cancer patients treated with or without 5-fluorouracil-based chemotherapy. Ann Oncol 19: 915-919

Tanaka-Nozaki M, Onda M, Tanaka N, Kato S (2001) Variations in 5 -fluorouracil concentrations of colorectal tissues as compared with dihydropyridine dehydrogenase (DPD) enzyme activities and DPD messenger RNA levels. Clin Cancer Res 7: 2783-2787

Tanaka-Nozaki M, Tapiri T, Tanaka N, Furukawa K, Takasaki H, Yoshimura K, Suzuki H, Naito Z, Sugizaki Y, Merk HF, Blömeke B, Kato S (2003) Intramural induction of thymidylate synthase mRNA in colorectal cancer patients: association with survival. Oncol Rep 10: 1425-1429 
Terrazzino S, Agostini M, Pucciarelli S, Pasetto LM, Friso ML, Ambrosi A, Lisi V, Leon A, Lise M, Nitti D (2006) A haplotype of the methylenetetrahydrofolate reductase gene predicts poor tumor response in rectal cancer patients receiving preoperative chemoradiation. Pharmacogenet Genomics 16: $817-824$

Ukida K, Hayashi K, Kuramochi H, Takasaki K (2001) Changes in intratumoral thymidylate synthase (TS) and dihydropyrimidine dehydrogenase (DPD) mRNA expression in colorectal and gastric cancer during continuous tegafur infusion. In J Oncol 19: 341-346

Ulrich CM, Bigler J, Velicer CM, Greene EA, Farin FM, Potter JD (2000) Searching expressed sequence tag databases: discovery and confirmation of a common polymorphism in the thymidylate synthase gene. Cancer Epidemiol Biomarkers Prev 9: 1381-1385

Ulrich CM, Robien K, Sparks R (2002) Pharmacogenetics and folate metabolism - a promising direction. Pharmacogenomics 3: 299-313

van Kuilenburg ABP (2004) Dihydropyrimidine dehydrogenase and the efficacy and toxicity of 5-fluorouracil. Eur J Cancer 40: 939-950

van Kuilenburg ABP, Muller EW, Haasjes J, Meinsma R, Zoetekouw L, Waterham HR, Baas F, Richel DJ, van Gennip AH (2001) Lethal outcome of a patient with a complete dihydropyrimidine dehydrogenase (DPD) deficiency after administration of 5-fluorouracil: frequency of the common IVS14+1G > A mutation causing DPD deficiency. Clin Cancer Res 7: $1149-1153$

Yamada H, Iinuma H, Watanabe $T$ (2008) Prognostic value of 5-fluorouracil metabolic enzyme genes in Dukes' stage B and C colorectal cancer patients treated with oral 5-fluorouracil-based adjuvant chemotherapy. Oncol Rep 19: 729-735

Ychou M, Duffour J, Kramar A, Debrigode C, Gourgou S, Bressolle F, Pinguet F (2003) Individual 5-FU dose adaptation in metastatic colorectal cancer: results of a phase II study using a bimonthly pharmcokinetically intensified LV5FU2 regimen. Cancer Chemother Pharmacol 52: 282 - 290

Young AM, Daryanani S, Kerr DJ (1999) Can pharmacokinetic monitoring improve clinical use of fluorouracil? Clin Pharmacokinet 36: 391-398

Zhang W, Press OA, Haiman CA, Yang DY, Gordon MA, Fazzone W, El-Khoueiry A, Iqbal S, Sherrod AE, Lurje G, Lenz HJ (2007) Association of methylenetetrahydrofolate reductase gene polymorphisms and sex-specific survival in patients with metastatic colon cancer. $J$ Clin Oncol 25: $3726-373$ 